Article

\title{
Engineering of a Potent Recombinant Lectin-Toxin Fusion Protein to Eliminate Human Pluripotent Stem Cells
}

\author{
Hiroaki Tateno *, Fumi Minoshima and Sayoko Saito \\ Biotechnology Research Institute for Drug Discovery (BRD), National Institute of Advanced Industrial Science \\ and Technology (AIST), Tsukuba Central 2, 1-1-1 Umezono, Tsukuba, Ibaraki 305-8568, Japan; \\ fumi-minoshima@aist.go.jp (F.M.); sayoko.saitou@aist.go.jp (S.S.) \\ * Correspondence: h-tateno@aist.go.jp; Tel.: +81-29-861-3125
}

Received: 19 June 2017; Accepted: 9 July 2017; Published: 10 July 2017

\begin{abstract}
The use of human pluripotent stem cells (hPSCs) such as human embryonic stem cells (hESCs) and human induced pluripotent stem cells (hiPSCs) in regenerative medicine is hindered by their tumorigenic potential. Previously, we developed a recombinant lectin-toxin fusion protein of the hPSC-specific lectin rBC2LCN, which has a $23 \mathrm{kDa}$ catalytic domain (domain III) of Pseudomonas aeruginosa exotoxin A (rBC2LCN-PE23). This fusion protein could selectively eliminate hPSCs following its addition to the cell culture medium. Here we conjugated rBC2LCN lectin with a $38 \mathrm{kDa}$ domain of exotoxin A containing domains $\mathrm{Ib}$ and II in addition to domain III (PE38). The developed rBC2LCN-PE38 fusion protein could eliminate 50\% of $201 \mathrm{~B} 7 \mathrm{hPSC}$ at a concentration of $0.003 \mu \mathrm{g} / \mathrm{mL}$ ( $24 \mathrm{~h}$ incubation), representing an approximately 556-fold higher activity than rBC2LCN-PE23. Little or no effect on human fibroblasts, human mesenchymal stem cells, and hiPSC-derived hepatocytes was observed at concentrations lower than $1 \mu \mathrm{g} / \mathrm{mL}$. Finally, we demonstrate that rBC2LCN-PE38 selectively eliminates hiPSCs from a mixed culture of hiPSCs and hiPSC-derived hepatocytes. Since rBC2LCN-PE38 can be prepared from soluble fractions of E. coli culture at a yield of $9 \mathrm{mg} / \mathrm{L}, \mathrm{rBC} 2 \mathrm{LCN}-\mathrm{PE} 38$ represents a practical reagent to remove human pluripotent stem cells residing in cultured cells destined for transplantation.
\end{abstract}

Keywords: lectin; pluripotent stem cells; tumorigenicity; regenerative medicine

\section{Introduction}

Human pluripotent stem cells (hPSCs) such as human embryonic stem cells (hESCs) [1] and human induced pluripotent stem cells (hiPSCs) [2] have immense potential as cell sources for regenerative medicine due to their self-renewal and pluripotency. However, major hurdles related to their tumorigenicity need to be overcome before they can be used for regenerative medicine purposes [3-5]. Given that as few as 100 transplanted hPSCs were demonstrated to form teratoma in a mouse model [6,7], the complete elimination of residual cells is therefore essential before hPSC-derived therapeutic cells can be used in clinical applications.

Previously, we found by lectin microarray that a lectin designated $\mathrm{rBC} 2 \mathrm{LCN}$ (recombinant N-terminal domain of BC2L-C lectin derived from Burkholderia cenocepacia) binds selectively to hPSCs, but not to non-hPSCs [8]. From a practical perspective, fluorescently-labeled rBC2LCN could be used as a reagent for the identification of hPSC s by flow cytometry analysis and microscopic observation [9]. One of the biggest advantages of $\mathrm{rBC} 2 \mathrm{LCN}$ is that the lectin can be used to strongly stain live hPSCs following its addition to the cell culture medium [9]. This staining is specific to hPSCs, and rapidly diminishes upon their differentiation. rBC2LCN binds to the Fuc $\alpha 1-2 \mathrm{Gal} \beta 1-3$ motif that is highly expressed on hPSCs $[8,10]$. Interestingly, $\mathrm{rBC} 2 \mathrm{LCN}$ was found to be endocytosed 
inside hPSCs upon binding to these cells. Taking advantage of this finding, we previously generated a recombinant lectin-toxin fusion protein by fusing $\mathrm{rBC} 2 \mathrm{LCN}$ with the $23 \mathrm{kDa}$ catalytic domain of Pseudomonas aeruginosa exotoxin A (PE), termed rBC2LCN-PE23, for the targeted elimination of hPSCs [11]. hiPSCs and hESCs were completely eliminated when treated for $24 \mathrm{~h}$ with $10 \mu \mathrm{g} / \mathrm{mL}$ of rBC2LCN-PE23.

To create more-potent reagents to eliminate hPSCs, here rBC2LCN is fused with a $38 \mathrm{kDa}$ domain of PE containing domains Ib and II in addition to domain III (PE38) [12]. The developed rBC2LCN-PE38 exhibited a robust cytotoxic effect on hPSCs compared to rBC2LCN-PE23. A concentration of $\mathrm{rBC} 2 \mathrm{LCN}-\mathrm{PE} 38$ as low as $0.003 \mu \mathrm{g} / \mathrm{mL}$ in the culture medium is sufficient for the $50 \%$ elimination of 201B7 hiPSCs, corresponding to a 556-fold higher toxicity against 201B7 hiPSCs than rBC2LCN-PE23. rBC2LCN-PE38 could thus be a cost-effective reagent to eliminate hPSCs present in hPSC-based cell therapy products.

\section{Results}

\subsection{Production of $r B C 2 L C N-P E 38$}

Previously, we developed rBC2LCN-PE23, in which rBC2LCN was fused with a $23 \mathrm{kDa}$ domain of PE, termed PE23, containing only domain III [11]. To increase the cytotoxicity of hPSCs, rBC2LCN (156 aa) was fused with a longer, $38 \mathrm{kDa}$ domain (PE38) containing domains II (113 aa) and $\mathrm{Ib}$ (27 aa) in addition to domain III (217 aa) (Figure 1A) [12]. The generated rBC2LCN-PE38 (526 aa) was expressed in E. coli and purified by affinity chromatography, with a yield obtained of $9 \mathrm{mg} / \mathrm{L}$ of bacterial culture. rBC2LCN-PE38 gave a major band at a higher molecular weight of $54 \mathrm{kDa}$ relative to $\mathrm{rBC} 2 \mathrm{LCN}(16 \mathrm{kDa})$ and rBC2LCN-PE23 (42 kDa) on SDS-PAGE under reducing conditions (Figure 1B).

A

IBC2LCN-PE23

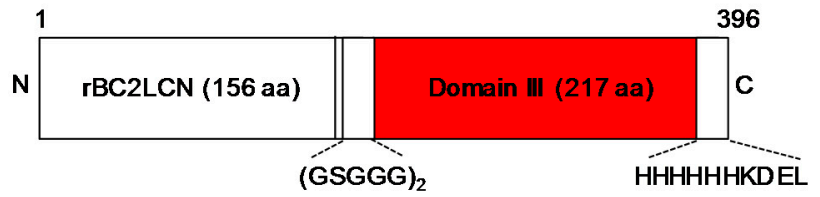

IBC2LCN-PE38

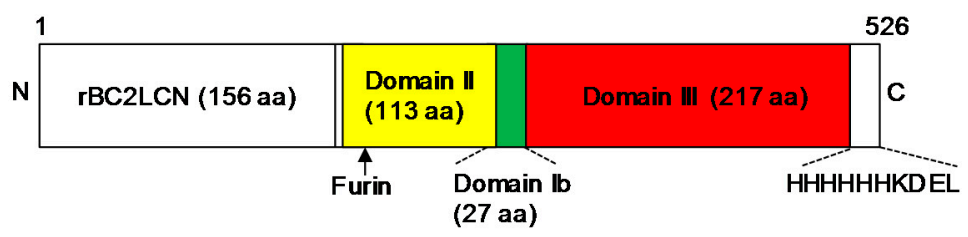

B

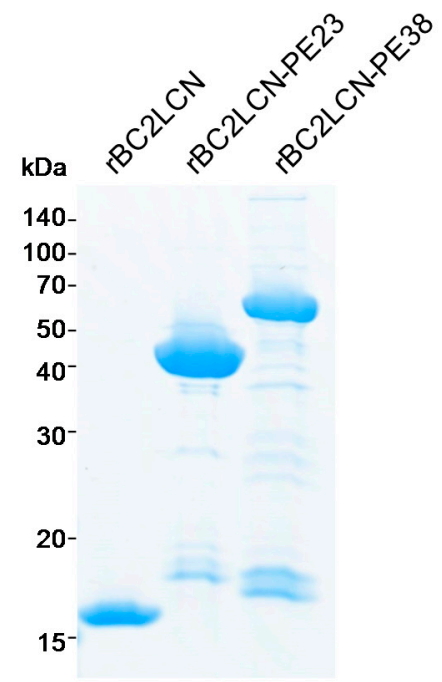

Figure 1. Production of rBC2LCN-PE38. (A) Domain structure of rBC2LCN-PE38 compared to rBC2LCN-PE23; (B) SDS-PAGE of purified rBC2LCN, rBC2LCN-PE23, and rBC2LCN-PE38. Four micrograms of purified rBC2LCN, rBC2LCN-PE23, or rBC2LCN-PE38 in the presence of 2-mercaptoethanol (2ME) were run on a 5-20\% acrylamide gel and stained with Coomassie G-250.

\subsection{Glycan-Binding Properties of $r B C 2 L C N-P E 38$}

We analyzed by glycoconjugate microarray the glycan-binding properties of rBC2LCN-PE38 compared to wild-type rBC2LCN and rBC2LCN-PE23 [13]. rBC2LCN-PE38 exhibited a similar glycan-binding specificity to both rBC2LCN and rBC2LCN-PE23, and bound to Fuc $\alpha 1-2 \mathrm{Gal} \beta 1-3$ motif-containing polyacrylamide (PAA) probes such as Fuc $\alpha 1-2 \mathrm{Gal} \beta 1-3 \mathrm{GlcNAc}-\mathrm{PAA}$ (H type1), 
Fuc $\alpha 1-2$ Gal $\beta 1-3 G a l N A c-P A A$ (H type3), and Fuc $\alpha 1-2$ Gal $\beta 1-3(F u c \alpha 1-4)$ GlcNAc-PAA (Le ${ }^{\text {b }}$ (Figure 2 and Table S1). The binding affinity of rBC2LCN-PE38 was also evaluated by quantitative analysis with frontal affinity chromatography [14]. The association constant $\left(K_{\mathrm{a}}\right)$ of rBC2LCN-PE38 for H type1- $p$ nitrophenol $(p N P)$ and $\mathrm{H}$ type3- $p \mathrm{NP}$ was $1.1 \times 10^{5}$ and $3.3 \times 10^{4} \mathrm{M}^{-1}$, respectively, which were similar to that of wild-type rBC2LCN (H type1- $p$ NP: $1.0 \times 10^{5} \mathrm{M}^{-1}$, H type3-pNP: $3.1 \times 10^{4} \mathrm{M}^{-1}$ ) [11]. Based on these results, we concluded that rBC2LCN-PE38 exhibits similar glycan-binding properties to wild-type rBC2LCN.

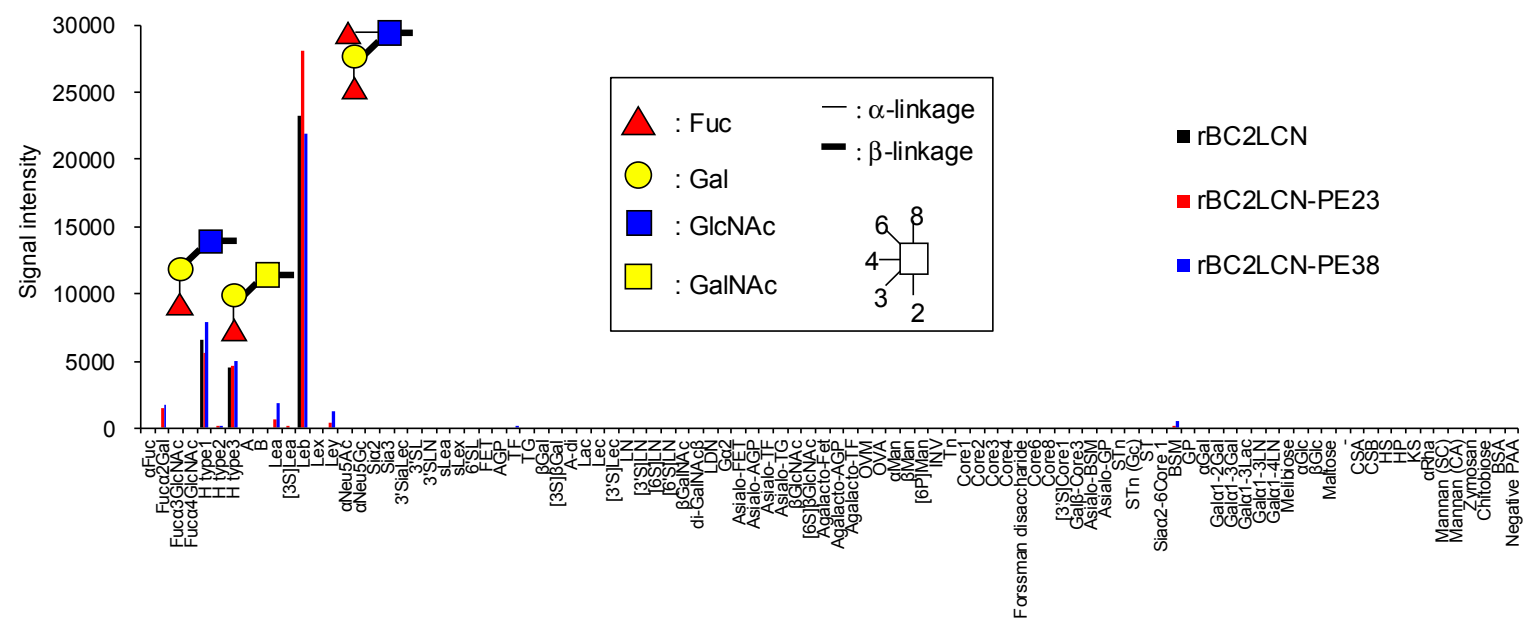

Figure 2. Glycan binding specificity of rBC2LCN-PE38. Cy3-labeled rBC2LCN, rBC2LCN-PE23, and rBC2LCN-PE38 were reacted with glycoconjugate microarray at $0.125 \mu \mathrm{g} / \mathrm{mL}$ overnight and scanned with an evanescent-field fluorescence scanner. Averages of the signals of triplicate spots are shown.

\subsection{Quantitative Effect of $r B C 2 L C N-P E 38$ on hiPSCs and Non-hPSCs}

We examined the cytotoxic effect of rBC2LCN-PE38 on hiPSCs and compared this to rBC2LCN-PE23. 201B7 hiPSCs were cultured with varying concentrations of rBC2LCN-PE23 or -PE38 $(0 \sim 100 \mu \mathrm{g} / \mathrm{mL})$ for $24 \mathrm{~h}$, and the viability of the cells was quantitated by measuring the metabolic activity of living cells. As shown in Figure 3, median lethal dose (LC50) of rBC2LCN-PE23 to 201B7 hiPSCs was $1.8 \mu \mathrm{g} / \mathrm{mL}$, whereas that of rBC2LCN-PE38 was $0.003 \mu \mathrm{g} / \mathrm{mL}$. This indicates a 556 -fold higher cytotoxicity of rBC2LCN-PE38 for hiPSCs than rBC2LCN-PE23. LC50 of rBC2LCN-PE38 for 253G1 hiPSCs was also similar $(0.003 \mu \mathrm{g} / \mathrm{mL})$ (Figure 3).

We also examined the effect of rBC2LCN-PE38 on the viability of non-hPSCs such as human dermal fibroblasts (hFibs) and human adipose-derived mesenchymal stem cells (hMSCs). LC50 of rBC2LCN-PE38 to hFibs and hMSCs was 48.4 and $9.2 \mu \mathrm{g} / \mathrm{mL}$, respectively, which correspond to 14,606and 2784-fold less active than to 201B7 hiPSCs (Figure 3).

\subsection{Effect of $r B C 2 L C N-P E 38$ on hiPSCs and Non-hPSCs Analyzed by Microscopy}

The effect of rBC2LCN-PE23 and rBC2LCN-PE38 on hiPSCs was also analyzed by cell staining and microscopy observations (Figure 4). 201B7 hiPSCs were cultured for $24 \mathrm{~h}$ with $0.1 \mu \mathrm{g} / \mathrm{mL}$ of rBC2LCN-PE23 or rBC2LCN-PE38 and cells were then stained using a LIVE/DEAD Cell Imaging Kit. Live cells are stained with cytoplasmic green fluorescence, and dying or dead cells are stained with nuclear red fluorescence. When $201 \mathrm{~B} 7 \mathrm{hiPSC}$ s were incubated with $0.1 \mu \mathrm{g} / \mathrm{mL}$ of rBC2LCN-PE23, the green fluorescence-positive live cells proliferated normally, and only a small number of red-stained dead cells could be identified, in agreement with the results obtained by metabolic measurement (Figure 3). In contrast, the green fluorescence-positive 201B7 hiPSCs disappeared when they were cultured in the presence of $0.1 \mu \mathrm{g} / \mathrm{mL} \mathrm{rBC2LCN}-\mathrm{PE} 38$ for $24 \mathrm{~h}$. Most of the dying or dead cells had detached from the cell culture flasks and were floating in the medium. In contrast, both hFibs and 
hMSCs proliferated normally and exhibited green fluorescence, but not red fluorescence, even after $24 \mathrm{~h}$ treatment with $1 \mu \mathrm{g} / \mathrm{mL}$ rBC2LCN-PE38 (Figure 5). These results demonstrate that rBC2LCN-PE38 has a negligible cytotoxic effect on non-hPSCs such as hMSCs and hFibs.

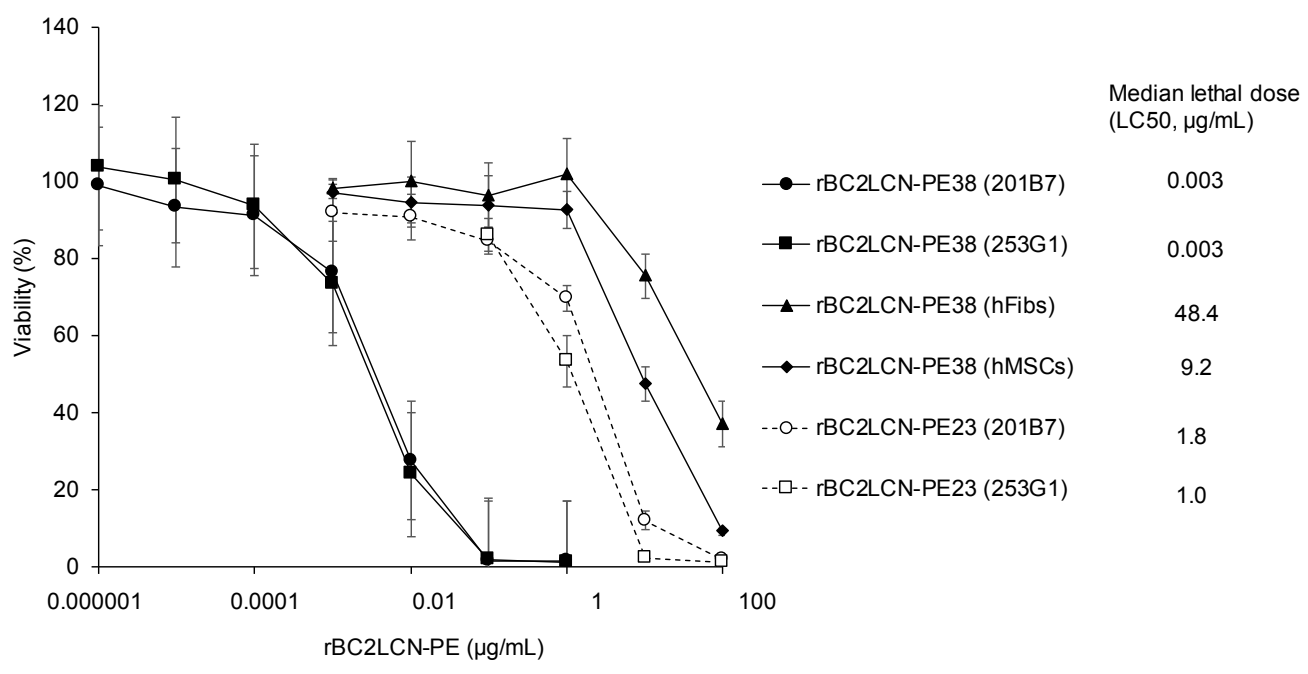

Figure 3. Quantitative effect of rBC2LCN-PE38 on the cell viability of human induced pluripotent stem cells (hiPSCs). 201B7 hiPSCs, 253 G1 hiPSCs, human dermal fibroblasts (hFibs), and human adipose-derived mesenchymal stem cells (hMSCs) were cultured with varying concentrations of rBC2LCN-PE38 or rBC2LCN-PE23. After $24 \mathrm{~h}$, the medium was replaced with fresh medium supplemented with $20 \mu \mathrm{L}$ of Cell Counting Kit (CCK)-8 solution, and the absorbance at $450 \mathrm{~nm}$ was measured after a further $4 \mathrm{~h}$ incubation. Viability (\%) was calculated from the absorbance at $450 \mathrm{~nm}$ of treated cells relative to untreated cells. Data are shown as mean $\pm \mathrm{SD}$ (for triplicate measurements). Median lethal dose (LC50) was calculated by GraphPad Prism7 software.

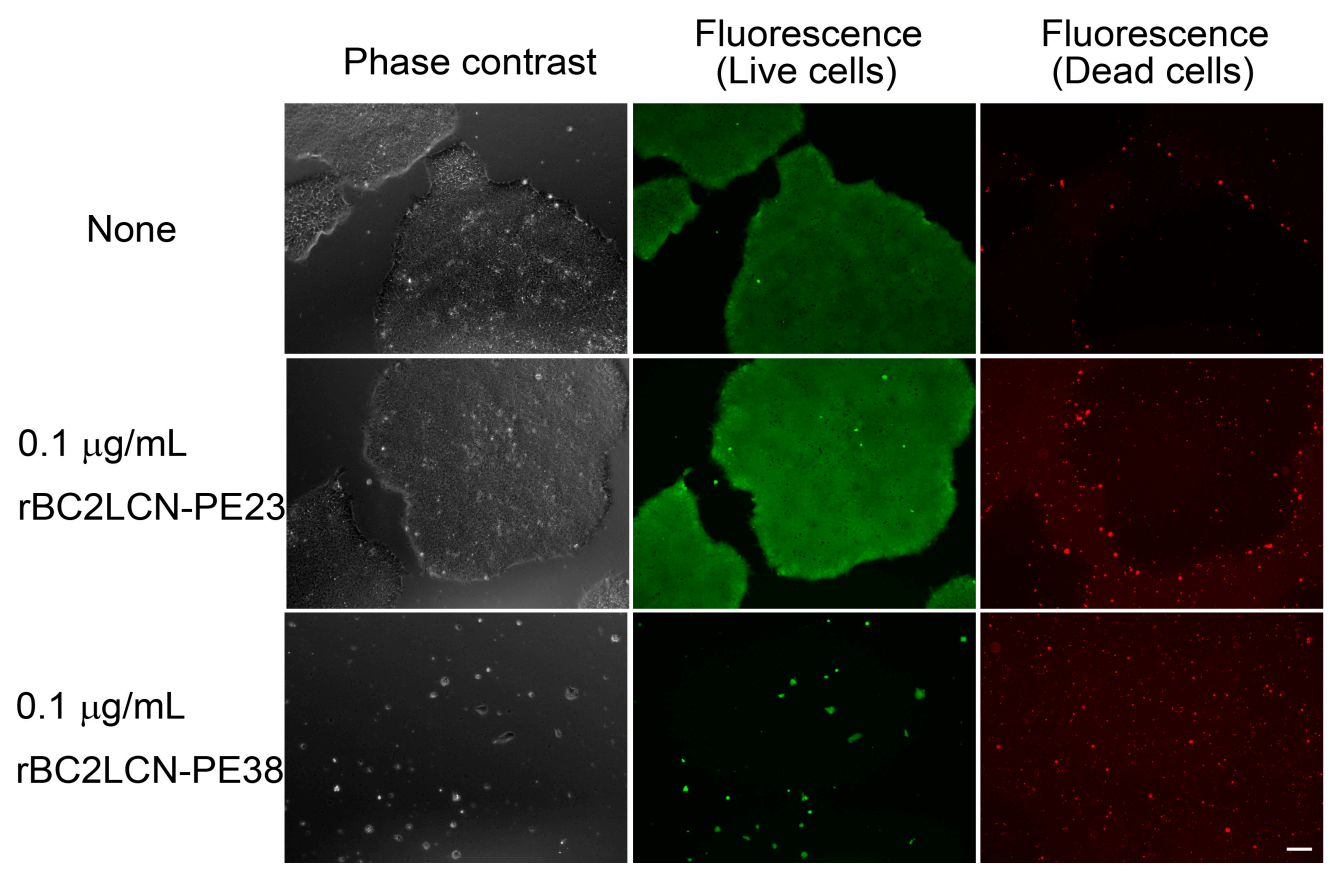

Figure 4. Effect of rBC2LCN-PE38 on the viability of hiPSCs. $201 B 7$ hiPSCs were cultured with or without $0.1 \mu \mathrm{g} / \mathrm{mL}$ of rBC2LCN-PE23 or rBC2LCN-PE38. After $24 \mathrm{~h}$, the cells were stained and observed with the aid of fluorescence microscopy. The live cell component showed cytoplasmic green fluorescence, whereas dying or dead cells exhibited nuclear red fluorescence. Scale bar: $100 \mu \mathrm{m}$. 


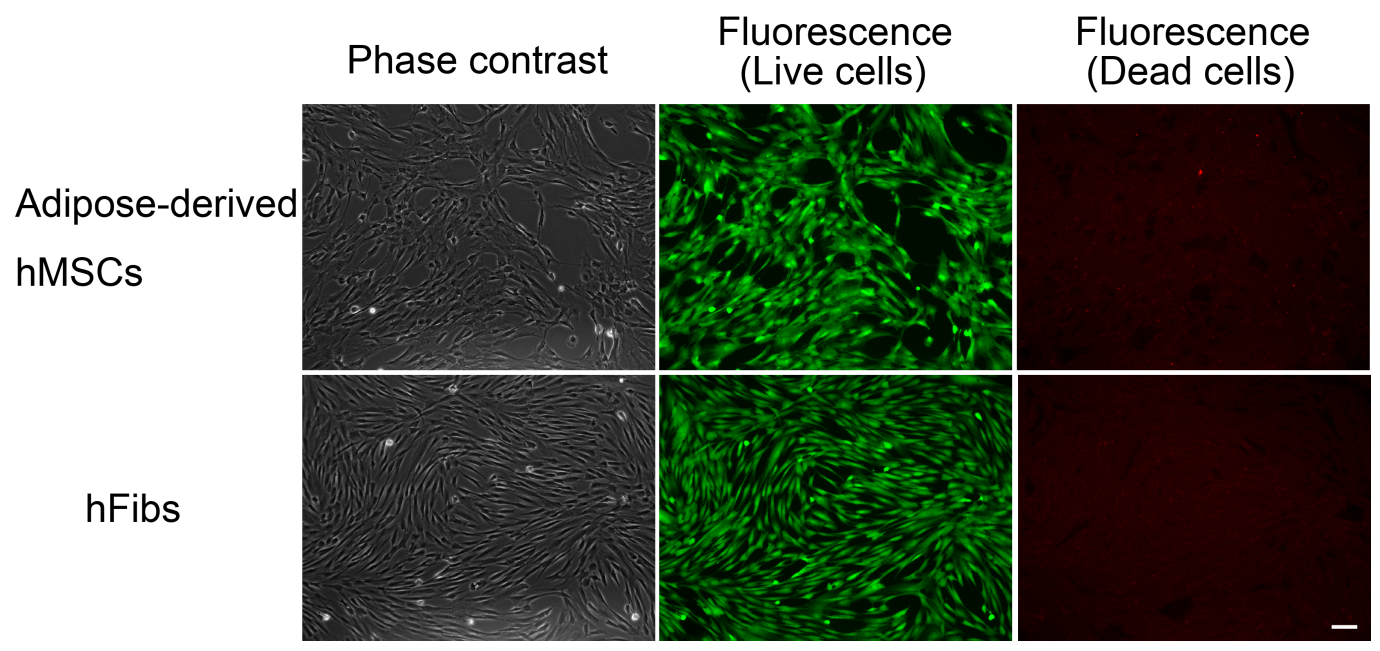

Figure 5. Effect of rBC2LCN-PE38 on the viability of differentiated cells. Human adipose-derived mesenchymal stem cells (hMSCs) and human dermal fibroblasts (hFibs) were cultured with $1 \mu \mathrm{g} / \mathrm{mL}$ of rBC2LCN-PE38. After $24 \mathrm{~h}$, cells were stained and observed by fluorescence microscopy. Live cells exhibited cytoplasmic green fluorescence, whereas dying or dead cells showed nuclear red fluorescence. Scale bar: $100 \mu \mathrm{m}$.

\subsection{Selective Elimination of hiPSCs Resident among hiPSC-Derived Hepatocytes}

Finally, we attempted to eliminate hPSCs present among hiPSC-derived hepatocytes. First, we analyzed the effect of rBC2LCN-PE38 on hiPSC-derived hepatocytes, which were cultured with varying concentrations of rBC2LCN-PE38 $(0-100 \mu \mathrm{g} / \mathrm{mL})$ for $24 \mathrm{~h}$ and their viability then quantitated by measuring the metabolic activity of living cells. As shown in Figure 6A, no effect on the viability of hiPSC-derived hepatocytes was observed at concentrations of rBC2LCN-PE38 up to $0.1 \mu \mathrm{g} / \mathrm{mL}$, but viability decreased at concentrations higher than $1 \mu \mathrm{g} / \mathrm{mL}$. We therefore decided to use a concentration of $0.1 \mu \mathrm{g} / \mathrm{mL}$ to eliminate hiPSCs present among hiPSC-derived hepatocytes. 201B7 hiPSCs cultured on 12-well plates were labeled with CellTracker ${ }^{\mathrm{TM}}$ Green CMFDA, and after removing residual fluorescence, fluorescently-labeled 201B7 hiPSCs were co-cultured at different percentages with hiPSC-derived hepatocytes in either the presence or absence of $0.1 \mu \mathrm{g} / \mathrm{mL} \mathrm{rBC2LCN-PE38.} \mathrm{After} 24 \mathrm{~h}$, cells were recovered and analyzed by flow cytometry (Figure 6B). In the absence of rBC2LCN-PE38, fluorescently-labeled 201B7 hiPSCs and unlabeled hiPSC-derived hepatocytes were detected in different ratios (43.2-0.29\% of 201B7 hiPSCs) (Figure 6B, top). In the presence of rBC2LCN-PE38, however, fluorescently-labeled 201B7 hiPSCs had been almost completely removed (Figure 6B, bottom). These results demonstrate that $\mathrm{rBC} 2 \mathrm{LCN}-\mathrm{PE} 38$ can selectively eliminate hiPSCs, even in a mixed cell population with different percentages of differentiated hiPSC-derived hepatocytes.

A

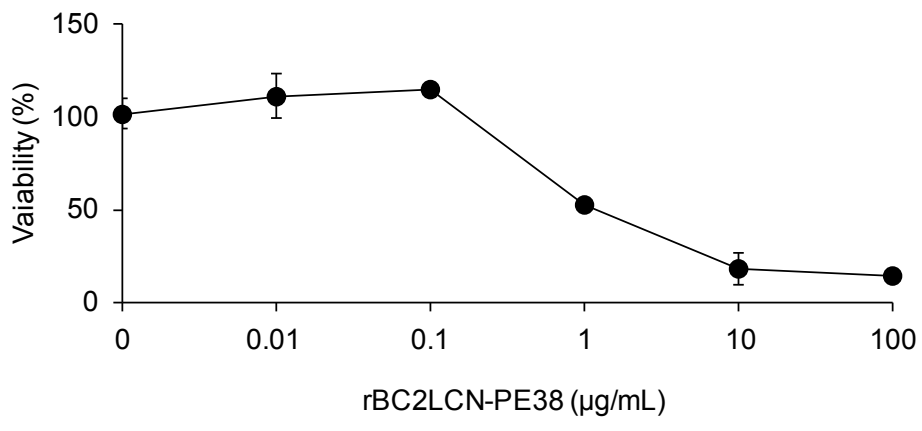

Figure 6. Cont. 


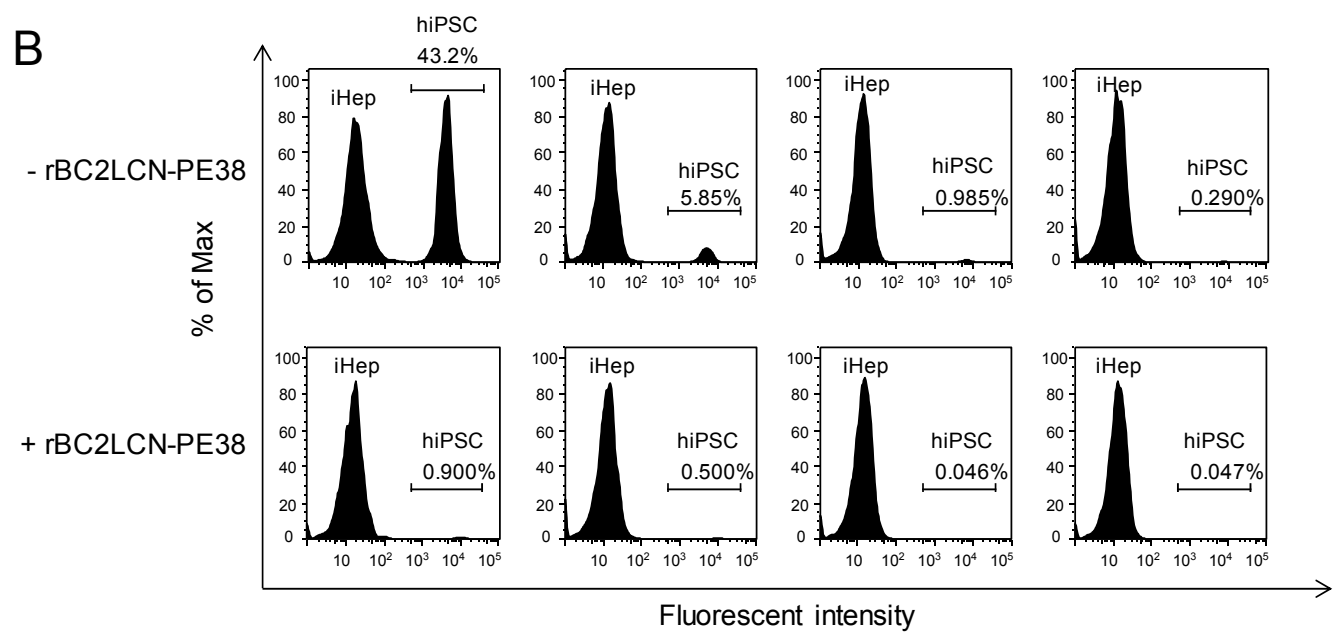

Figure 6. Selective killing by rBC2LCN-PE38 of hiPSCs resident among hiPSC-derived hepatic cells. (A) Effect of rBC2LCN on the viability of hiPSC-derived hepatocytes. 201B7 hiPSCs were cultured with different concentrations of rBC2LCN-PE38. After $24 \mathrm{~h}$, the medium was replaced with fresh medium supplemented with $20 \mu \mathrm{L}$ of CCK-8 solution, and the absorbance at $450 \mathrm{~nm}$ was measured after a further $4 \mathrm{~h}$ incubation. Viability (\%) was calculated from the absorbance at $450 \mathrm{~nm}$ of treated cells relative to untreated cells. Data are shown as mean \pm SD (for triplicate measurements); (B) $201 \mathrm{~B} 7$ hiPSCs were cultured and fluorescently labeled with $20 \mu \mathrm{M}$ of CellTracker ${ }^{\mathrm{TM}}$ Green CMFDA. After washing to remove residual fluorescence, hiPSC-derived hepatocytes (iHep) were mixed in different percentages and co-cultured in either the presence (lower panels) or absence (upper panels) of $0.1 \mu \mathrm{g} / \mathrm{mL}$ of rBC2LCN-PE38. After $24 \mathrm{~h}$, flow cytometry data were acquired.

\section{Discussion}

We have shown here that a fusion protein consisting of $\mathrm{rBC} 2 \mathrm{LCN}$ with a $38 \mathrm{kDa} \mathrm{PE}$ domain-termed rBC2LCN-PE38 - could be successfully produced in a fully active form from soluble fractions of $E$. coli culture medium. rBC2LCN-PE38 retained a glycan-binding activity similar to that of wild-type rBC2LCN and rBC2LCN-PE23, even though the molecular size of PE38 (38 kDa) is much larger than that of rBC2LCN lectin $(16 \mathrm{kDa})$. In addition, the yield of rBC2LCN-PE38 $(9 \mathrm{mg}$ per liter of culture medium) was similar to that of rBC2LCN-PE23 (10 mg/L). Notably, the generated rBC2LCN-PE38 showed an approximately 556-fold higher cytotoxic activity to 201B7 hiPSCs than the previously developed rBC2LCN-PE23 [11]. PE is composed of 613 amino acids containing three domains: domain Ia with receptor binding activity, domain II with translocation activity, and domains $\mathrm{Ib}$ and III with ADP-ribosyltransferase activity. PE23 contains only domain III, whereas PE38 contains domain II as well as domains Ib and III. Therefore, the higher cytotoxic activity of rBC2LCN-PE38 depends largely on the presence of domains II and Ib. Although the functions of these two domains are not clearly understood, they were reported to be required for cell killing activity [12]. PE38 is the most commonly employed cytotoxic fragment of PE. Several immunotoxins incorporating PE38 have already reached the clinical trial stage for treating B-cell malignancies, lung cancer, and hematologic malignancies [12].

rBC2LCN-PE38 was produced in E. coli. Recombinant proteins produced in E. coli might contain residues of E. coli, such as lipopolysaccharide. Although wild-type rBC2LCN prepared in E. coli gave no visible toxicity to hiPSCs [9], we should pay attention in terms of toxicity when we use rBC2LCN-PE38 for cell culture or regenerative medicine.

Hepatocyte transplantation is one of the most attractive approaches for the treatment of patients with liver failure. However, donor sources of human hepatocytes are limited, and thus novel sources of hepatocytes are highly necessary. From this perspective, hepatocytes derived from hiPSCs are attractive cell sources for hepatocyte transplantation, since hiPSCs can be proliferated in a perpetual manner. 
One of the major concerns for the use of hiPSC-derived hepatocytes, however, is that tumorigenic hiPSCs residing in the hiPSC-derived hepatocyte population could form tumors in transplanted patients. We showed here that $0.1 \mu \mathrm{g} / \mathrm{mL}$ of $\mathrm{rBC} 2 \mathrm{LCN}-\mathrm{PE} 38$ could selectively remove hiPSCs from a mixed cell population of hiPSCs and hiPSC-derived hepatocytes. Since rBC2LCN-PE38 shows a 556-fold higher cytotoxicity to hPSCs compared to rBC2LCN-PE23, and their production yields are similar, rBC2LCN-PE38 could be expected to be a cost-effective reagent to remove hPSCs from hPSC-derived cell therapy products.

\section{Materials and Methods}

\subsection{Construction, Expression, and Purification of rBC2LCN-PE38}

A $38 \mathrm{kDa}$ domain of PE (PE38) containing domain Ib (27 aa), domains II (113 aa), and domain III (217 aa) was inserted via NheI and XhoI into an expression vector of $\mathrm{pET} 27 \mathrm{~b}$ at the C-terminus of an N-terminal domain of BC2L-C identified from Burkholderia cenocepacia (rBC2LCN) (1-156 aa) (Figure 1) (Weldon and Pastan, 2011). A C-terminal 6xHis tag (PPHHHHHH) was also added for protein purification in case the expressed recombinant lectin could not be purified by sugar-immobilized column from the soluble fractions of $E$. coli, and endoplasmic reticulum (ER) retention signal sequence (KDEL) for efficient intracellular trafficking to the ER. The total number of amino acids was 526, and the calculated average molecular weight was 55,666 Da. The generated rBC2LCN-toxin fusion protein was designated "rBC2LCN-PE38".

The expression plasmid of rBC2LCN-PE38 was transformed into E. coli BL21 CodonPlus (DE3)-RIL. The transformed E. coli was cultured in L-Broth medium containing $10 \mu \mathrm{g} / \mathrm{mL}$ kanamycin at $37^{\circ} \mathrm{C}$ until the optical density (OD) at $600 \mathrm{~nm}$ reached 0.4. rBC2LCN-PE38 expression was induced by the addition of $1 \mathrm{mM}$ IPTG at $20^{\circ} \mathrm{C}$ for $24 \mathrm{~h}$. The following procedures were performed at $4{ }^{\circ} \mathrm{C}$. The E. coli cells were harvested by centrifugation at $4450 \times g$ for $30 \mathrm{~min}$ and lysed by sonication in phosphate buffered saline containing EDTA and Triton X-100 (PBSET: $6 \mathrm{mM} \mathrm{Na}_{2} \mathrm{HPO}_{4} \cdot 12 \mathrm{H}_{2} \mathrm{O}, 1.4 \mathrm{mM} \mathrm{KH} \mathrm{PO}_{4}, 140 \mathrm{mM}$ $\mathrm{NaCl}$ pH 7.0, $1 \mathrm{mM}$ EDTA, $0.1 \%$ Triton X-100) containing a protease inhibitor cocktail (Nacalai tesque). After centrifugation at $24,910 \times \mathrm{g}$ for $30 \mathrm{~min}$, supernatants were applied onto L-fucose-Sepharose and the bound rBC2LCN-PE38 was eluted with $0.2 \mathrm{M}$ L-fucose in PBSE $\left(6 \mathrm{mM} \mathrm{Na}_{2} \mathrm{HPO}_{4} \cdot 12 \mathrm{H}_{2} \mathrm{O}\right.$, $1.4 \mathrm{mM} \mathrm{KH}_{2} \mathrm{PO}_{4}, 140 \mathrm{mM} \mathrm{NaCl} \mathrm{pH}$ 7.0, 1 mM EDTA). The purified rBC2LCN-PE38 was dialyzed against PBS. The protein concentration was measured by BCA protein assay (Thermo Scientific), and the purity was analyzed by electrophoresis using $17 \%$ XV pantera MP Gel (DRC).

\subsection{SDS-PAGE}

Four micrograms of purified lectins were incubated at $95{ }^{\circ} \mathrm{C}$ for $5 \mathrm{~min}$ in the presence of 2-mercaptoethanol and run on a 5-20\% polyacrylamide gel (DRC). The gel was then stained with Bio-Safe Coomassie G-250 Stain (Bio-Rad, Hercules, CA, USA).

\subsection{Frontal Affinity Chromatography}

The principle and protocol for frontal affinity chromatography have been described previously $[14,15]$. Briefly, rBC2LCN-PE38 was immobilized onto NHS-activated Sepharose 4FF (GE) and packed into a miniature column (inner diameter, $2 \mathrm{~mm}$; length, $10 \mathrm{~mm}$, bed volume, $31.4 \mu \mathrm{L}$; Shimadzu, Kyoto, Japan) and connected to a high-performance liquid chromatograph (Shimadzu, Kyoto, Japan). Varying concentrations of $\mathrm{H}$ type1- $p \mathrm{NP}$ and $\mathrm{H}$ type3- $p \mathrm{NP}$ were injected into the column, and the elution front was determined relative to that of negative control LacNAc ( $N$-acetyl lactosamine) $-p \mathrm{NP}$, referred to $\mathrm{V}-\mathrm{V}_{0}$. Finally, $\mathrm{B}_{\mathrm{t}}(\mathrm{nmol})$ and $K_{\mathrm{d}}(\mu \mathrm{M})$ values were obtained from Woolf-Hofstee plots. 


\subsection{Cell Culture}

$201 B 7$ and 253G1 hiPSCs were cultured in mTeSR1 (StemCell Technologies, Vancouver, BC, Canada) on cell culture plates coated with Matrigel (BD Biosciences) $[2,16]$. The human ES cell line, H1, was cultured in mTeSR1 according to the WiCell Feeder Independent Pluripotent Stem Cell Protocols provided by the WiCell Research Institute (www.wicell.org). $201 \mathrm{~B} 7$ and H1 hESCs were differentiated by culturing them in mTeSR 1 containing $10 \mu \mathrm{M}$ of retinoic acid for 10 days. hFibs and hADSCs were cultured in MesenPRO RS medium. Cells were counted with a hemocytometer, a Vi-CELL Cell Viability Analyzer (Beckman coulter, Tokyo, Japan), or a TC20 Automated Cell Counter (Bio-Rad, Hercules, CA, USA). hiPSCs and hESCs used in this study were confirmed to have the ability to form teratoma and to be positive for both anti-SSEA4 and rBC2LCN [17].

\subsection{Cell Viability Assay}

The cytotoxicity of rBC2LCN-PE38 was analyzed using a LIVE/DEAD Cell Imaging Kit (Molecular Probes). Cells were cultured in mTeSR1 on 12-well plates coated with Matrigel in the presence or absence of rBC2LCN-PE38 $(0.1$ and $1 \mu \mathrm{g} / \mathrm{mL})$. After $24 \mathrm{~h}$, they were stained with Live Green (A) and Dead Red (B) reagents according to the manufacturer's instructions and observed under an Axio Vert.A1 (Carl Zeiss, Oberkochen, Germany) or BZ-9000 fluorescence microscope.

The cytotoxicity of rBC2LCN-PE38 or -PE23 was also analyzed using a Cell Counting Kit-8 (Dojindo). Cells were cultured in $500 \mu \mathrm{L}$ mTeSR1 on 24-well plates coated with Matrigel in the presence of different concentrations of rBC2LCN-PE38. After $24 \mathrm{~h}$, the culture medium was replaced with $200 \mu \mathrm{L}$ of fresh medium and $20 \mu \mathrm{L}$ of CCK-8 solution, and after a further $4 \mathrm{~h}$ incubation in a $\mathrm{CO}_{2}$ incubator, the absorbance was measured at $450 \mathrm{~nm}$. Median lethal dose (LC50) was calculated by GraphPad Prism7 software (GraphPad Software, Inc., La Jolla, CA, USA).

\subsection{Flow Cytometry}

201B7 hiPSCs were cultured in mTeSR1 on 12-well plates coated with Matrigel. Adherent cells were fluorescently labeled with $20 \mu \mathrm{M}$ CellTracker ${ }^{\mathrm{TM}}$ Green CMFDA (Life Technologies, Carlsbad, CA, USA) and incubated at $37^{\circ} \mathrm{C}$ for $45 \mathrm{~min}$. After replacing the medium, cells were further cultured at $37^{\circ} \mathrm{C}$ for $30 \mathrm{~min}$. Unlabeled hiPSC-derived hepatocytes were seeded and co-cultured in either the presence or absence of $10 \mu \mathrm{g} / \mathrm{mL}$ of rBC2LCN-PE38. After $24 \mathrm{~h}$, cells were recovered and centrifuged at $5000 \mathrm{rpm}$ for $1 \mathrm{~min}$. After removing the supernatant, the cells were suspended in $1 \mathrm{~mL}$ of PBS containing $1 \%$ bovine serum albumin. Finally, flow cytometry data were acquired on a CytoFLEX (BECKMAN COULTER) and analyzed using FlowJo software (FLOWJO, Ashland, OR, USA).

\section{Conclusions}

In conclusion, we have generated a lectin-toxin fusion protein by fusing an hPSC-specific lectin with a $38 \mathrm{kDa}$ PE, termed rBC2LCN-PE38, which showed 556-fold higher cytotoxic activity to 201B7 hiPSCs compared to the previously developed rBC2LCN-PE23. Since rBC2LCN-PE38 can be produced in an E. coli expression system at a yield of $9 \mathrm{mg} / \mathrm{L}$, this lectin-toxin fusion protein could serve as a practical reagent to remove hPSCs from cultured cells prior to the use of differentiated cells in regenerative medicine applications.

Supplementary Materials: The supplementary materials are available online.

Acknowledgments: We thank Kayo Kiyoi for technical assistance. Human iPS cell lines 201 B7 (HPS0063) and 253G1 (HPS0002) were obtained from the RIKEN Bioresource Center. This work supported in part by funding for the project "Development of Cell Manufacturing and Processing Systems for Commercialization of Regenerative Medicine" from the Japan Agency for Medical Research and Development, AMED.

Author Contributions: H.T. wrote the paper, designed the experiments, and analyzed the data. S.S. and F.M. performed the experiments.

Conflicts of Interest: The authors declare no conflict of interest. 


\section{References}

1. Thomson, J.A.; Itskovitz-Eldor, J.; Shapiro, S.S.; Waknitz, M.A.; Swiergiel, J.J.; Marshall, V.S.; Jones, J.M. Embryonic stem cell lines derived from human blastocysts. Science 1998, 282, 1145-1147. [CrossRef] [PubMed]

2. Takahashi, K.; Tanabe, K.; Ohnuki, M.; Narita, M.; Ichisaka, T.; Tomoda, K.; Yamanaka, S. Induction of pluripotent stem cells from adult human fibroblasts by defined factors. Cell 2007, 131, 861-872. [CrossRef] [PubMed]

3. Ben-David, U.; Benvenisty, N. The tumorigenicity of human embryonic and induced pluripotent stem cells. Nat. Rev. Cancer 2011, 11, 268-277. [CrossRef] [PubMed]

4. Goldring, C.E.; Duffy, P.A.; Benvenisty, N.; Andrews, P.W.; Ben-David, U.; Eakins, R.; French, N.; Hanley, N.A.; Kelly, L.; Kitteringham, N.R.; et al. Assessing the safety of stem cell therapeutics. Cell Stem Cell 2011, 8, 618-628. [CrossRef] [PubMed]

5. Lee, A.S.; Tang, C.; Rao, M.S.; Weissman, I.L.; Wu, J.C. Tumorigenicity as a clinical hurdle for pluripotent stem cell therapies. Nat. Med. 2013, 19, 998-1004. [CrossRef] [PubMed]

6. Gropp, M.; Shilo, V.; Vainer, G.; Gov, M.; Gil, Y.; Khaner, H.; Matzrafi, L.; Idelson, M.; Kopolovic, J.; Zak, N.B.; et al. Standardization of the teratoma assay for analysis of pluripotency of human ES cells and biosafety of their differentiated progeny. PLoS ONE 2012, 7, e45532. [CrossRef] [PubMed]

7. Hentze, H.; Soong, P.L.; Wang, S.T.; Phillips, B.W.; Putti, T.C.; Dunn, N.R. Teratoma formation by human embryonic stem cells: Evaluation of essential parameters for future safety studies. Stem Cell Res. 2009, 2, 198-210. [CrossRef] [PubMed]

8. Tateno, H.; Toyota, M.; Saito, S.; Onuma, Y.; Ito, Y.; Hiemori, K.; Fukumura, M.; Matsushima, A.; Nakanishi, M.; Ohnuma, K.; et al. Glycome diagnosis of human induced pluripotent stem cells using lectin microarray. J. Biol. Chem. 2011, 286, 20345-20353. [CrossRef] [PubMed]

9. Onuma, Y.; Tateno, H.; Hirabayashi, J.; Ito, Y.; Asashima, M. rBC2LCN, a new probe for live cell imaging of human pluripotent stem cells. Biochem. Biophys. Res. Commun. 2013, 431, 524-529. [CrossRef] [PubMed]

10. Sulak, O.; Cioci, G.; Delia, M.; Lahmann, M.; Varrot, A.; Imberty, A.; Wimmerova, M. A TNF-like trimeric lectin domain from Burkholderia cenocepacia with specificity for fucosylated human histo-blood group antigens. Structure 2010, 18, 59-72. [CrossRef] [PubMed]

11. Tateno, H.; Onuma, Y.; Ito, Y.; Minoshima, F.; Saito, S.; Shimizu, M.; Aiki, Y.; Asashima, M.; Hirabayashi, J. Elimination of tumorigenic human pluripotent stem cells by a recombinant lectin-toxin fusion protein. Stem Cell Rep. 2015, 4, 811-820. [CrossRef] [PubMed]

12. Weldon, J.E.; Pastan, I. A guide to taming a toxin-recombinant immunotoxins constructed from Pseudomonas exotoxin A for the treatment of cancer. FEBS J. 2011, 278, 4683-4700. [CrossRef] [PubMed]

13. Tateno, H.; Mori, A.; Uchiyama, N.; Yabe, R.; Iwaki, J.; Shikanai, T.; Angata, T.; Narimatsu, H.; Hirabayashi, J. Glycoconjugate microarray based on an evanescent-field fluorescence-assisted detection principle for investigation of glycan-binding proteins. Glycobiology 2008, 18, 789-798. [CrossRef] [PubMed]

14. Tateno, H.; Nakamura-Tsuruta, S.; Hirabayashi, J. Frontal affinity chromatography: Sugar-protein interactions. Nat. Protoc. 2007, 2, 2529-2537. [CrossRef] [PubMed]

15. Nakamura, S.; Yagi, F.; Totani, K.; Ito, Y.; Hirabayashi, J. Comparative analysis of carbohydrate-binding properties of two tandem repeat-type Jacalin-related lectins, Castanea crenata agglutinin and Cycas revoluta leaf lectin. FEBS J. 2005, 272, 2784-2799. [CrossRef] [PubMed]

16. Nakagawa, M.; Koyanagi, M.; Tanabe, K.; Takahashi, K.; Ichisaka, T.; Aoi, T.; Okita, K.; Mochiduki, Y.; Takizawa, N.; Yamanaka, S. Generation of induced pluripotent stem cells without Myc from mouse and human fibroblasts. Nat. Biotechnol. 2008, 26, 101-106. [CrossRef] [PubMed]

17. Tateno, H.; Onuma, Y.; Ito, Y.; Hiemori, K.; Aiki, Y.; Shimizu, M.; Higuchi, K.; Fukuda, M.; Warashina, M.; Honda, S.; et al. A medium hyperglycosylated podocalyxin enables noninvasive and quantitative detection of tumorigenic human pluripotent stem cells. Sci. Rep. 2014, 4, 4069. [CrossRef] [PubMed]

Sample Availability: Samples of the compounds are available from the authors. 